\title{
The Taming Wicked Problems Framework: A plausible biosocial contribution to 'ending AIDS by 2030'
}

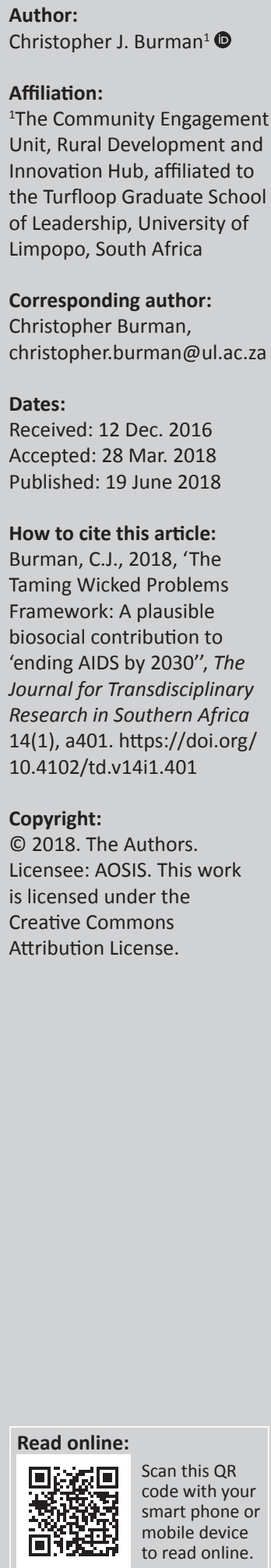

\begin{abstract}
In 2014, the Joint United Nations Programme on HIV/AIDS (UNAIDS) published the Gap Report, which states that a new biosocial response to the HIV and AIDS epidemic is required to reinforce the biomedical strategy - Vision 90:90:90 - which is designed to end AIDS by 2030. This article provides a descriptive account of how a community-university partnership developed and piloted an innovative, transdisciplinary approach to HIV and AIDS management that could represent a nascent biosocial candidate to reinforce the biomedical strategy. The biosocial strategy has been labelled as the Taming Wicked Problems Framework that is influenced by ontological perspectives associated with complexity theory. The article focuses on how the Taming Wicked Problems Framework was developed by co-opting and repurposing management techniques associated with complexity into an action-oriented HIV and AIDS combination intervention. Three years after the pilot began, the Taming Wicked Problems Framework continues to provision the partnership with opportunities to 'tame' non-linear, biosocial aspects of the HIV and AIDS epidemic in rural South Africa. However, with the benefit of hindsight, there are some improvements and caveats that are highlighted so that future applications will be more robust. It is suggested that the Taming Wicked Problems Framework could represent one localised biosocial response that could contribute to ending AIDS by 2030.
\end{abstract}

\section{Introduction}

This article provides a descriptive account of how the Taming Wicked Problems Framework (henceforth 'the Framework') was developed. The practical purpose of this article is to provide a holistic statement about the Framework, with some reference to the key findings, followed by some critical reflections. The strategic purpose of the article is to open a conversation about developing a biosocial response - which the Joint United Nations Programme on HIV/AIDS (UNAIDS) has called for - that makes sense to grass-roots communities. The common theme which links the practical and strategic objectives is the development of a mechanism to identify and respond to both linear and non-linear dynamics that influence the HIV and AIDS biosocial environment.

The article is structured as follows: firstly, background information about the pilot is provided; secondly, the meta-theoretical and pragmatic factors that influenced the design are presented; thirdly, the Framework is described; fourthly, the discussion section provides extra theoretical layers that have been consolidated during the learning process and, fifthly, a tentative statement is provided about the potential of the Framework to contribute to the biosocial response that UNAIDS has called for. The article concludes by suggesting that the Framework enables the nonlinear complexity that is now associated with HIV and AIDS to be responded to. It is also suggested that the Framework could represent one localised, transdisciplinary biosocial response that can contribute to ending AIDS by 2030.

\section{Background information The partnership}

The partnership that initiated and implemented the pilot is between the University of Limpopo's Community Engagement Unit and the Waterberg Welfare Society (WWS 2017). The partnership has been reported on in detail elsewhere and so only a brief overview is provided next (Burman \& Aphane 2016a; 2016b).

In the last quarter of 2013, discussions between the community-university partners identified one challenge that appeared to be 'wicked'. The challenge was the legacy of the Abstain, Be faithful, 
Condomise campaign (ABC) which - despite being phased out by the National Department of Health (NDoH) continued to frustrate the work of WWS (Burman \& Aphane 2016a). Because of the continued frustration that WWS was reporting about the influence or influences of the ABC-legacy, reducing its impact became the practical focus of the partnership. The partnership agreed that the challenge was a 'wicked problem' and should therefore be tackled by attempting to build resilience to the challenge, rather than trying to solve it.

\section{Vision 90:90:90}

Vision 90:90:90 means that the global community:

aim for $90 \%$ of people living with HIV knowing their HIV status, $90 \%$ of people who know their status receiving treatment and $90 \%$ of people on HIV treatment having a suppressed viral load so their immune system remains strong and they are no longer infectious. (UNAIDS 2014a:10)

Vision 90:90:90 has been made possible by the unprecedented medical breakthroughs of the previous decade. These breakthroughs transformed HIV from being a life-threatening condition to a chronic disease if people living with HIV strictly adhere to antiretroviral therapy (ART) (Teeraananchai et al. 2016).

However, despite the unique opportunities afforded by the biomedical breakthroughs, UNAIDS argued that (1) 'it is necessary to invest in communities ... [to] ensure that the AIDS response is people-centred and take it to new levels' and (2) 'we have to come up with a biosocial response and not just a medical response to end the AIDS epidemic' (UNAIDS 2014b:300, 305). They also argued that the new biosocial response had to be capable of incorporating the 'complex life challenges' experienced by many people at risk of HIV and AIDS (UNAIDS 2014b:118) which required that there should be a focus 'not just at the national level but also at the local level' (UNAIDS 2014b:301).

\section{'Wicked problems'}

Wicked problems are difficult to 'identify and define'; have 'no definitive solution that will resolve them'; solutions are 'not correct or incorrect but rather they range from better to worse'; solutions 'cannot be tested in the short term and are impossible to determine once and for all'; often attempts to solve a wicked problem 'changes the problem but does not necessarily alleviate it'; each wicked problem can 'be explained in numerous ways, and one's choice of explanation determines the solutions that will be generated' - and whilst attempts to overcome wicked problems may change the dynamics of the situation, the efforts can sometimes generate unexpected outputs that are 'potentially harmful' (adapted from Sharts-Hopko 2013:104). Wicked problems are now associated with intractable challenges situated across multiple disciplines including, inter alia health promotion (Signal et al. 2013), HIV and AIDS (Smith et al. 2013) and

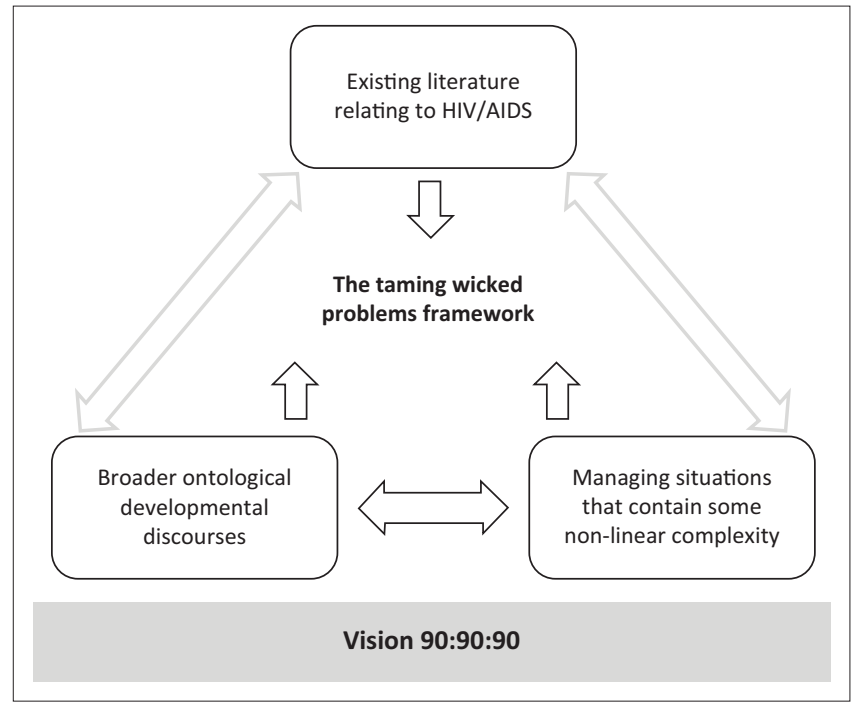

FIGURE 1: Factors that influenced the development of the Framework.

nursing (Hutchinson et al. 2015). The dominant consensus within these perspectives reflects a comment by Churchman (1967:B-141) that it is difficult to solve wicked problems using conventional strategies, but it is possible to 'tame their growl'.

Because of the consensus that the challenge was 'wicked', the university component of the partnership used existing materials to design a prototype intervention. Three interrelated factors influenced the design of the prototype that was further influenced by the adoption of Vision 90:90:90 in 2014 by the South African NDoH (Figure 1).

Existing HIV and AIDS literature was used as a starting point, augmented by two meta-theoretical influences: the broader ontology of developmental discourses and complexity theory.

\section{Previous human immuno virus management strategies}

In 2010 a supplementary issue of AIDS Care included a summary of four dominant biosocial HIV management strategies (Campbell \& Cornish 2010), as summarised in Table 1.

Campbell and Cornish (2010:1570) argue that one of the reasons that the 'first and second-generation' HIV-related interventions failed to achieve the intended impact is because they were often 'conceived by external experts' and imposed on communities in 'top-down' ways. As a result, they:

fail to resonate with the worldviews and perceived needs and interests of their target groupings, or to take adequate account of the complex social relations into which programs are inserted. (Campbell \& Cornish 2010:1570)

This argument is based upon lessons learnt from global experiences and gave rise to the 'third and fourth-generation' approaches that were influenced by the argument that 'community involvement is a vital pre-condition for creating 
TABLE 1: Four generations of human immuno virus and acquired immune deficiency syndrome management.

\begin{tabular}{ll}
\hline $\begin{array}{l}\text { HIV and AIDS } \\
\text { management typology }\end{array}$ & Brief description \\
\hline $\begin{array}{l}\text { First generation: promoting } \\
\text { HIV awareness }\end{array}$ & $\begin{array}{l}\text { Focused on the individual, based on the premise } \\
\text { that people were fundamentally ignorant about HIV } \\
\text { transmission pathways, so didactic health education } \\
\text { was prescribed as the strategy of choice, justified } \\
\text { through a rational actor lens. }\end{array}$ \\
$\begin{array}{ll}\text { Second-generation: } \\
\text { peer education }\end{array}$ & $\begin{array}{l}\text { Behaviour change strategies emphasised the } \\
\text { importance of peer education as a mechanism to } \\
\text { continue the linear transmission of knowledge about } \\
\text { HIV and AIDS combined with dialogue to facilitate } \\
\text { ideas about how to apply this knowledge as a } \\
\text { risk-reduction strategy. }\end{array}$ \\
$\begin{array}{l}\text { An effort to move beyond the individual as the unit } \\
\text { of analysis by harnessing agency 'to build a } \\
\text { community mobilisation } \\
\text { collective, community response, through their full } \\
\text { participation in the design, implementation and } \\
\text { leadership of health programmes, and by forging } \\
\text { supportive partnerships with significant groups both } \\
\text { inside and outside of the community' (Campbell \& } \\
\text { Cornish 2010:1572). }\end{array}$ \\
$\begin{array}{l}\text { Fourth-generation: changing } \\
\text { the context in which } \\
\text { community mobilisation } \\
\text { efforts are initiated }\end{array}$ & $\begin{array}{l}\text { Improving the context within which community } \\
\text { mobilisation happened focused on the 'symbolic, } \\
\text { material and relational context' of mobilisation } \\
\text { (Campbell \& Cornish 2010:1569). }\end{array}$ \\
\hline
\end{tabular}

Source: Campbell and Cornish 2010:1571-1575

"health-enabling" social environments' (Campbell \& Cornish 2010:1570). However, a literature review of the impact of community mobilisation in middle- and low-income countries on HIV prevention indicated that 'no significant results were found for reductions of HIV incidence or prevalence', although there was 'suggestive evidence for sex worker groups' (Cornish et al. 2014:2128). These findings were mirrored by the South African National HIV Prevalence, Incidence and Behaviour Survey, 2012, which presented evidence of the poor track record in relation to HIV incidence rates in South Africa during the previous decade (Shisana et al. 2014).

More recent data also indicate that the biosocial progress towards ending AIDS are not being achieved quickly enough (Mayer, Shisana \& Beyrer 2016) - with the exception being new infections in children because of the gains made in prevention of mother-to-child transmission (UNAIDS 2016b). Despite the opportunities that the biomedical innovations are contributing to the ambition of ending AIDS (Vella 2015), UNAIDS continues to emphasise the necessity of reinvigorating biosocial HIV prevention strategies to reinforce the biomedical opportunities (UNAIDS 2016a). This is reinforced by other commentators who argue that the biosocial strategies 'must be regarded not as complementary, but as integral, to biomedical interventions' (emphasis added, Govender \& Poku 2016:iv).

\section{Previous biosocial human immuno virus management strategies from the perspective of the Framework design}

From the pilot perspective, these findings and arguments prompted a question about whether the types of biosocial innovations that could contribute to ending AIDS should be generated from within the dominant biosocial HIV management paradigm, or whether a disruptive, paradigm shifting innovation was justified. In order to gauge whether, or not, a disruptive innovation was appropriate, a perspective based on broader developmental discourses was developed and applied during the pilot.

\section{The ontology of developmental discourses}

Cole (1999:222) argues that 'what we believe the world to be, ontology, which defines the questions we wish to ask, determines how we study and understand existence, epistemology' (emphasis in original). For Cole, there are three dominant perspectives that influence the ontological, hence epistemological, parameters of developmental enquiry. The three perspectives include 'independent actors', whose potentials are biologically endowed; 'dependent actors', whose potentials are a product of 'adaptive socialisation' and 'interdependent actors, whose potentials evolve as emergent properties with social experience' (emphasis added, Cole 2003:327-332).

These three categories were used as a heuristic to gain insights into the variable perspectives about beliefs in human potentials - and possible biases - within the firstto fourth-generation approaches to HIV management. The heuristic suggests that the first- and second-generation approaches to HIV management are biased towards the independent actor category because they relied on the assumption that people would respond to new knowledge, independent of societal influences. The third- and fourthgeneration approaches to HIV management appeared to be biased towards the dependent actor perspective because social environments were considered to either enable or constrain 'effective community mobilisation' (Campbell \& Cornish 2010:1574).

\section{The ontology of developmental discourses from the perspective of the Framework design}

This brief summary of the assumed potentials of people in communities to engage with the HIV and AIDS epidemic generated two areas that required further consideration. Firstly, if it had been assumed by the designers of the first- to fourth-generation approaches that the potentials of people living in communities are restricted to either the independent or dependent actor category, was this a discrete bias that was adversely influencing outcomes? Secondly, if, as Cole suggests, people influence the social environment - and the social environment influences people and their behaviours how could this abstract, interdependent concept be built on to improve outcomes during the pilot? The possibility of moving beyond the ontological parameters of the 'first to fourth-generation' approaches to HIV management (Cole's independent and dependent categories) provided one metatheoretical focus of enquiry for the pilot to determine if additional impact could be derived from applying the interdependent ontological perspective.

The other meta-theoretical query was linked to the association between wicked problems and non-linear complexity, hinted at by Strogatz (2003:182) who argued that 'every major unresolved problem in science - from consciousness to cancer to the collective craziness of the economy, is non-linear'. In the context of HIV and AIDS, this comment is underscored by Brown et al. (2015:1) who argued that if we rely exclusively 
'on the current linear but disconnected approaches to [HIV] intervention research and evidence we will miss the potential to achieve and understand [complex] system-level synergies'.

\section{The human immunodeficiency virus and complexity}

In 2008, the incumbent Executive Director of UNAIDS argued that 'HIV prevention must be able to deal with complexity .... [and] tools need to be designed to capture these dynamics' (Piot et al. 2008:853). Despite this argument, the literature suggested that there had been very few attempts to address biosocial HIV management using mechanisms associated with complexity theory (for one rare example, see Auerbach, Parkhurst \& Caceres 2011). The absence of literature relating to the non-linear complexities that influence biosocial HIV management strategies seemed to be an anomaly in the face of a statement in the Gap Report that in 'many instances, marginalised populations face complex life challenges, risks and obstacles on multiple fronts' (emphasis added, UNAIDS 2014b:118) and committed 12 chapters to explain the complex challenges experienced by those populations (UNAIDS 2014b:119 279). This reinforced the idea that attempting to explore the 'wicked problem' identified by the community partner using a complexity perspective had potential merit.

\section{Complex systems}

The earliest writing about complexity is generally associated with a short essay authored by Warren Weaver (1948). In the period imbetween, complexity has developed into a fragmented international field of scholarship. For the sake of brevity, only the aspects of complexity that have influenced the development of the Framework are outlined in Table 2.

Table 2 highlights some of the dominant characteristics of complex systems. One of the most striking characteristics of complex systems is that they do not produce entirely random, nor entirely predictable, outputs or outcomes. This means that whilst it is not possible to produce replicable results that fit the criteria associated with evidence informed best practices, it is possible to manage them (Ramalingham 2013; Snowden \& Boone 2007). The other aspects of complex systems that are relevant include (1) complex systems are made up of multiple agents that interact through feedback loops (Dunn et al. 2016); (2) agents are understood to mean any entity that influences the system (Sturmberg \& Martin 2009); (3) the outcomes, or outputs, associated with complex systems emerge from the feedback interactions of the agents within the system (Shiell, Hawe \& Gold 2008), and (4) the feedback processes that maintain the system are self-regulating (Pincus \& Metten 2010), selforganising (Lee 1997) and self-sustaining, or - to use jargon from complexity, autopoietic - (Chettiparamb 2007). Emergence from a complex system is thus mediated by discrete and indeterminate interactions of the agents within the system which is represented in Figure 2 using an iceberg metaphor.
TABLE 2: Aspects relating to complexity that have influenced the development of the Framework.

\begin{tabular}{|c|c|}
\hline Concept & Description \\
\hline $\begin{array}{l}\text { The 'initial conditions' of a complex } \\
\text { system influence future outcomes. }\end{array}$ & $\begin{array}{l}\text { The initial condition of a system 'can } \\
\text { increasingly restrain present and future } \\
\text { choices' (Koch, Eisend \& Petermann } \\
2009: 67) \text {, meaning that the future } \\
\text { trajectory of the system is partially } \\
\text { constrained, hence not entirely random. }\end{array}$ \\
\hline $\begin{array}{l}\text { Complex systems are robust and } \\
\text { dynamical. }\end{array}$ & $\begin{array}{l}\text { 'Complex systems can survive the removal } \\
\text { of parts by adapting to the change' } \\
\text { (Rickles, Hawe \& Shiell 2007:933). }\end{array}$ \\
\hline $\begin{array}{l}\text { Despite being robust, complex systems } \\
\text { are unstable, hence do contain } \\
\text { unpredictable potentials. }\end{array}$ & $\begin{array}{l}\text { 'Agents and the system constrain one } \\
\text { another, especially over time (Snowden \& } \\
\text { Boone 2007:73) making complex systems } \\
\text { unstable which means they demonstrate a } \\
\text { degree of unpredictability' (Stirzaker et al. } \\
\text { 2010:600). }\end{array}$ \\
\hline $\begin{array}{l}\text { Complex systems are generated and } \\
\text { sustained by multiple feedback loops } \\
\text { between the agents within a system } \\
\text { demonstrating indeterminate, yet } \\
\text { patterned characteristics. }\end{array}$ & $\begin{array}{l}\text { 'These information exchange } \\
\text { relationships, when sufficient in number } \\
\text { and connection, lead to complex feedback } \\
\text { dynamics including positive (change } \\
\text { expanding) feedback, negative feedback } \\
\text { (change dampening), threshold effects, } \\
\text { coupling dynamics (e.g. synchronisation), } \\
\text { and hierarchical dynamics' (Pincus \& } \\
\text { Metten 2010:354). }\end{array}$ \\
\hline \multirow[t]{2}{*}{$\begin{array}{l}\text { Complex systems demonstrate some } \\
\text { non-linearity. }\end{array}$} & $\begin{array}{l}\text { Some 'interactions are non-linear, and } \\
\text { minor changes can produce } \\
\text { disproportionately major consequences' } \\
\text { and vice versa (emphasis added, Snowden } \\
\text { \& Boone 2007:71). }\end{array}$ \\
\hline & $\begin{array}{l}\text { 'Combination therapy .... uses a cocktail of } \\
\text { three drugs that works precisely because } \\
\text { the immune response and viral dynamics } \\
\text { are non-linear. The three drugs taken in } \\
\text { combination are much more effective than } \\
\text { the sum of the three taken separately' } \\
\text { (emphasis added, Ramalingham } \\
\text { 2013:228). }\end{array}$ \\
\hline
\end{tabular}

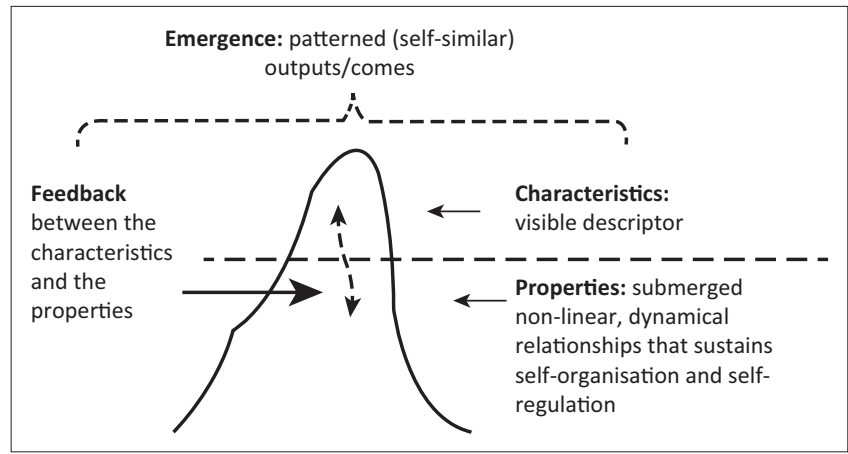

Source: Adapted from Inayatullah 1998; also see Burman and Aphane 2016b:571

FIGURE 2: The discrete interactions that influence emergence from within complex systems.

The emergence is a result of the feedback interactions between both the surface descriptor - that is the characteristics of a phenomenon, such as adherence to medication - and the submerged properties that co-constitute the feedback dynamics between the agents within the system that generate and sustain the characteristics of the phenomenon. Consequently, management of complex systems requires altering the submerged feedback dynamics between the agents in order to change the properties of the system, which in turn, alters the subsequent emergence (Coleman et al. 2007).

\section{Complexity theory from the perspective of the Framework design}

The application of complexity theory to the pilot enabled the HIV and AIDS epidemic to be formulated as the consequences (outputs and outcomes) that emerge from the 
feedback dynamics within, and between the submerged components of the 'human-virus-environment' that sustain the HIV and AIDS system (Burman, Aphane \& Delobelle 2015:15). This formulation began a process of considering that one of the likely mediators of the outcomes of the pilot would rely upon initially working with the discrete, submerged, properties of the dynamical system, rather than focusing exclusively on the surface descriptors.

To achieve this required insights into how the submerged feedback dynamics influence emergent outputs and outcomes. The dynamical feedback processes within complex systems are influenced by strange attractors (henceforth 'attractors'), which means that attractors represent one focus of the management strategy (Snowden \& Boone 2007). Attractors represent recurring convergences of agents towards multiple equilibria zones within a complex system which influence emergence (Pincus \& Metten 2010; Sturmberg \& Martin 2010). 'Strange attractors are reflected in patterns of behaviour, that is, shapes in space or movements over time, which are never exactly repeated but are always similar to each other' because they are fractal in structure (Stacey 2003:44). Consequently, as attractors are discrete forces that mediate self-similar emergence, they represent a loci of change opportunities when managing complex systems - and thus became a strategic analytical focus during the pilot (Burman \& Aphane 2016a)

\section{From theory to implementation: Managing complexity}

From the pilot perspective, it was not only necessary to gain insights about how attractors - dominant potential loci of change - influence systems, it was also necessary to identify a mechanism to simultaneously manage both non-linear and linear emergence during the pilot. The primary source that influenced the development of a mechanism to manage emergence was a theoretical article in the Harvard Business Review called Aleader's framework for decision making (Snowden $\&$ Boone 2007). The authors of the article introduced a management heuristic called the Cynefin framework that enables leaders to identify both non-linear and linear challenges and provides a management response typology for each category (Figure 3).

The two domains on the right-hand side of the Cynefin framework - complicated and obvious - represent ordered, predictable, linear decision-making contexts and the two on the left-hand side - complex and chaos - represent unordered, unpredictable, non-linear decision-making domains. The Cynefin framework has been applied in multiple contexts (Dettmer 2011; Elford 2012; Sturmberg \& Martin 2008; Van Beurden et al. 2013) and the intention was to co-opt it into the HIV challenge that the partnership was focusing on.

Responding to the different domains required that the partnership understood how to implement each management response typology. The best, good and novel practices within

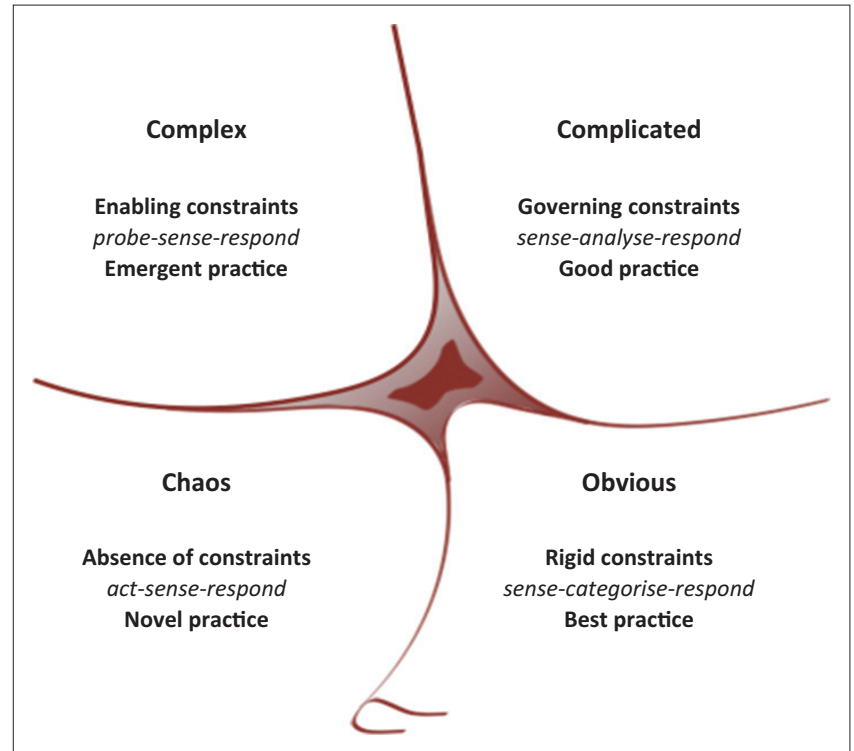

Source: Based on https://en.wikipedia.org/wiki/Cynefin\#/media/File:Cynefin_as_of_1st_ June_2014.png, reproduced with permission

FIGURE 3: The Cynefin framework.

the obvious, complicated and chaos domains were easy to understand. However, the emergent practice in the complex domain required further investigation. Snowden and Boone (2007:72) argue that in complex scenarios, it is only possible to 'understand why things happen only in retrospect'. However, they also argue that when attempting to identify opportunities to manage complex situations, it is possible to identify 'instructive patterns' if 'safe to fail' experiments are undertaken (Snowden \& Boone 2007:72).

\section{Safe to fail experimentation}

Safe to fail experiments - contra fail-safe strategies - represent low risk, ethically sound experiments of which about $50 \%$ are expected to fail, but the learning from the failure can be exploited to improve the more successful experiments (Dickens 2012; Huertas 2014). When working with complexity, this is a viable strategy for developing future management opportunities because complex systems are robust and have the capacity 'to reorganise and recover from change and disturbance without changing to other states' (Ahern 2011:341). The notion of a safe to fail management response to complex challenges was therefore integrated into the Framework design.

\section{The Taming Wicked Problems Framework}

During the pilot, the Framework was developed from a combination of concepts into a coherent entity through experiential learning and critical reflection (Figure 4).

In the sections below, a brief description and the theoretical foundation of each phase (1-5) is provided. Reflections about these different phases - and how some of them can be improved - follow in the discussion. 


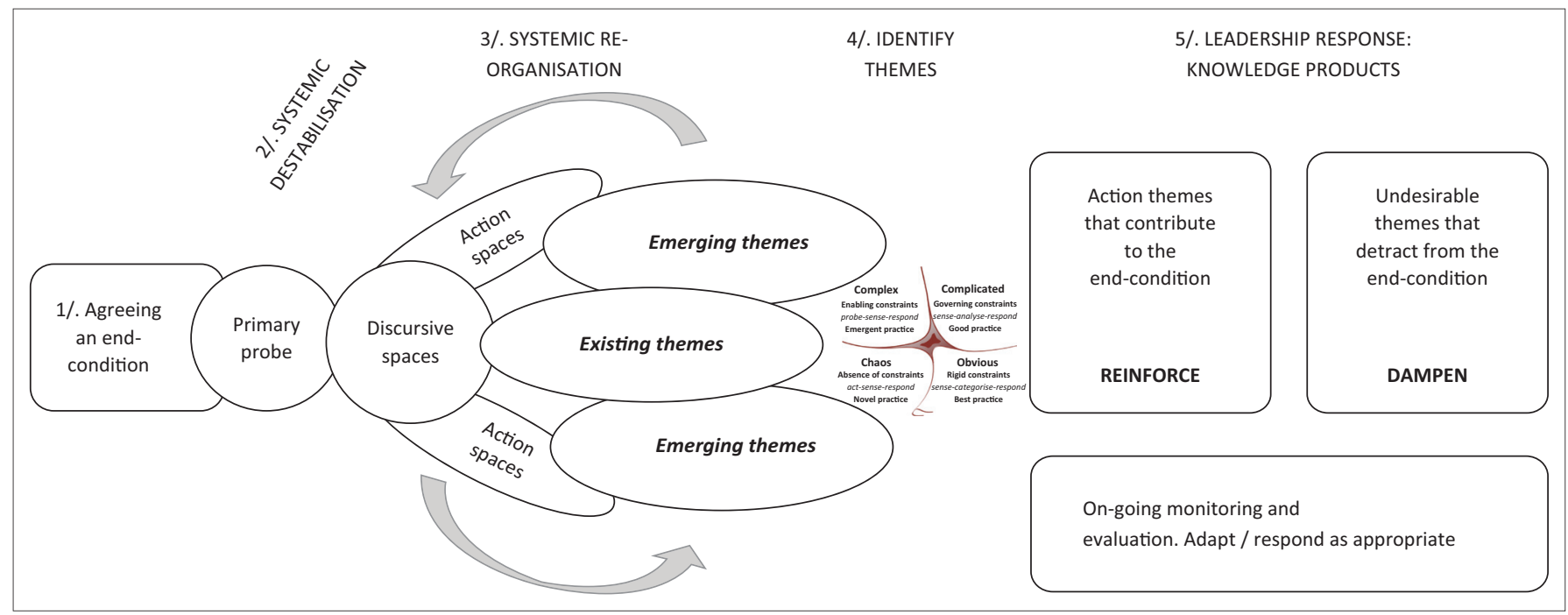

Source: Adapted from Burman, Aphane and Mollel, 2017:57

FIGURE 4: The Taming Wicked Problems Framework.

\section{Determining if the system is complex and agreeing an end-condition (Phase 1)}

Non-linearity - inputs which produce disproportional outputs - is a useful indicator of a complex system. In the case of HIV and AIDS management, 'billions of dollars have been poured into HIV and AIDS interventions' (Campbell \& Cornish 2010:1570), yet incidence rates in South Africa remain stubbornly high (Shisana et al. 2014). The disproportionately small impact from the billions of dollars suggests that the HIV and AIDS epidemic is systemically robust in the face of attempts reduce risk and is an indicator of non-linear complexity. Once it has been agreed that the system contains some non-linear complexity it is necessary for the partnership to agree an end-condition.

An 'end-condition is imagined and not a specific end-state' because complex systems are unpredictable; thus, it is not possible to determine the precise 'end-state' - but it is possible to predict the desired parameters of emergence. In this instance, because the 90:90:90 ambition represents reducing the aggregate global viral load to the lowest possible level, it was decided by the partnership that the end-condition for the pilot would be a 'reduced aggregate community viral load' (Burman \& Aphane 2016a:95).

\section{Systemic destabilisation (Phase 2)}

The next phase involves destabilising the environment within which the wicked problem is situated and has been labelled the primary probe (Figure 4). It is possible to ethically destabilise the system because complex systems are inherently unstable, yet robust enough to recover, through adaptive processes that may 'create new order' (Dunn et al. 2016:4). In this instance, the primary probe was an educational package called 'A-3B-4C-T' that focused on the human-virus-environment interactions (Leadership Training Resource Centre 2014). The A-3B-4C-T educational package was delivered to WWS' leaders to provision them with new perspectives about the HIV and AIDS epidemic (Burman \& Aphane 2016a).

\section{Systemic re-organisation (Phase 3)}

If the primary probe has been effective, a period of systemic reorganisation occurs as people affected by the destabilisation begin to make sense of the changes and act on them. This process reflects a series of indeterminate iterations that can be associated at a theoretical level with frame theory (Goffman 1974), including 'unlearning' existing frames (Rogers et al. 2013:4) and reconstructing new frames which are influenced by the primary probe. This process involves sense-making (Dervin 1998) and closely resembles theories associated with experiential, adult learning (Wals 2007). In this instance, the systemic re-orientation catalysed new attractors which WWS began to incorporate into their work.

\section{Identifying emergent attractors (Phase 4)}

In order to identify the existing and emergent attractors, a qualitative analytical methodology called causal layered analysis - which is designed 'to deconstruct complex social issues' (Bishop \& Dzidic 2014:13) - was applied 10 months after the A-3B-4C-T educational package had been delivered. In this instance, six attractors that contributed to the endcondition ambition and three that detracted from it were identified (Table 3).

Table 3 provides an overview of the attractors which were influencing the local HIV and AIDS environment 10 months after the A-3B-4C-T educational package was delivered. The emergence of new attractors indicated that WWS was developing emergent perspectives with regard to the ABC-legacy.

\section{Decision-making: the Cynefin framework (between phases 4 and 5)}

The Cynefin framework is a decision-making heuristic that is designed to determine whether or not a challenge is 
TABLE 3: Emergent attractors and associated influences on social practices and/ or cognitive processes that contributed to the end-condition.

\begin{tabular}{ll}
$\begin{array}{l}\text { Attractors that contributed to } \\
\text { the agreed end-condition }\end{array}$ & $\begin{array}{l}\text { Attractors that detracted from the } \\
\text { agreed end-condition }\end{array}$ \\
\hline $\begin{array}{l}\text { Reframing of HIV from being a death } \\
\text { sentence, to a chronic condition }\end{array}$ & \\
$\begin{array}{l}\text { The viral load } \\
\text { Relating the new knowledge to personal } \\
\text { experiences }\end{array}$ & $\begin{array}{l}\text { Inconsistent messaging within the } \\
\text { community }\end{array}$ \\
$\begin{array}{l}\text { The origins of HIV, that is, zoonosis } \\
\text { Comunity influences }\end{array}$ & $\begin{array}{l}\text { The need to develop more tools and } \\
\text { techniques to improve the impact of }\end{array}$ \\
$\begin{array}{l}\text { New tools and techniques that were being } \\
\text { introduced into WWS' work }\end{array}$ & $\begin{array}{l}\text { WWS' work in the community } \\
\text { Consistent messaging by WWS to } \\
\text { their clients }\end{array}$ \\
\hline
\end{tabular}
their clients

Source: Adapted from Burman and Aphane 2016a:100

aFor further information about the emergence of the HI virus from simian immunodeficiency viruses (SIVs), see Sharp and Hahn (2011)

exclusively linear or contains some non-linearity, so that appropriate management decisions can be determined (Snowden \& Boone 2007). In this instance, it was also used as a monitoring and evaluation device which was designed to identify movement within the Cynefin framework as an indicator of the utility of the Framework at that stage in the pilot (Burman \& Aphane 2016a).

\section{The leadership response (Phase 5) \\ Reinforcement of emergent attractors that contribute to the end-condition}

Influenced by the outputs of the Cynefin framework and the resources available to the partnership, it was decided that four of the attractors - labelled as 'action themes', Figure 4 - would be focused on using safe to fail reinforcement techniques. The four attractors included: reframing of HIV from being a death sentence, to a chronic condition; the viral load; relating the new knowledge to personal experiences and the origins of HIV. The focus was to reinforce the presence of these attractors within the WWS HIV and AIDS environment and simultaneously to develop new tools and techniques in response to the demand that WWS had identified. This was achieved by supporting the Education and Awareness Department with resources to integrate the attractors into their working practices with support groups for people living with HIV.

\section{Dampening undesirable attractors}

It was decided that despite the significance of the community influences as an attractor that detracted from achieving the end-condition, there was no identifiable mechanism to dampen it. This was influenced by both WWS' experiences and reinforced by the observation that both the first- to fourth-generation HIV and AIDS management approaches had produced 'no significant results' (Cornish et al. 2014:2128). Instead of expending resources on attempts to dampen this attractor, the decision was to reinforce the attractors that were believed to offer the most opportunities to contribute to ending AIDS and to monitor the community influence attractor to see if it altered during the subsequent work.

The sections above have described the context of the pilot and an overview of how the Framework was conceptualised and implemented. During that period, the university component of the partnership continued to reflect on the process from multiple theoretical perspectives. In the discussion, these reflections are presented prior to considering whether the Framework represents a nascent biosocial response that could contribute to ending AIDS.

\section{Discussion}

The discussion is split into two sections. The first is a reflection on the practical aspect of the intervention design and the second relates to the strategic component - UNAIDS' call for a new biosocial response to reinforce the biomedical opportunities that are believed to be sufficient to end AIDS by 2030 .

\section{A practical reflection on the effectiveness of the Framework}

\section{Determining if the system is complex and agreeing an} end-condition (Phase 1)

In this instance, the ABC-legacy did appear to contain some non-linear complexity and showed similarities with many of the characteristics associated with a wicked problem. However, with retrospect, the early analysis was crude and could be improved by applying the Cynefin framework at the beginning of the intervention. The Cynefin framework can be used to break down the challenge into its constituent parts and then categorising the parts into the appropriate non-linear and linear domains. If the challenge contains some non-linear components, then this provides a clear indicator that the challenge is complex, which could improve this aspect of the Framework.

\section{The primary probe and systemic destabilisation (Phase 2)}

In this instance, the A-3B-4C-T educational package was used as the primary probe in order to destabilise the system in order to catalyse downstream systemic re-organisation and the outcome was satisfactory. However, from the Framework design perspective, relying on one mechanism to destabilise the system is risky. In future, a safe to fail approach will be applied so that multiple possible destabilisers can be identified.

\section{Systemic re-organisation (Phase 3) from an engaged, action-research perspective}

There are two practical issues that relate to this phase that are relevant. The first is the importance of ensuring that the reorganisation process reflects the local context and the second is the ambiguity that the expression sense-making represents.

\section{The importance of the local context}

It is important that the systemic re-organisation process reflects the local context so that the emergent attractors make sense in that geographical location. The reason for this is that the local context represents the 'initial conditions' which 'increasingly restrain[s] present and future choices' (Koch et al. 2009:67, also see Table 2). This means that the future systemic trajectory is partially constrained, hence neither 
precisely predictable, nor entirely random. Contaminating the intervention with non-local perspectives - such as the university's perspectives - risks introducing frames that do not make sense in a particular context and could jeopardise the relevance of the subsequent outputs and outcomes (Olivier de Sardan, Diarra \& Moha 2017).

\section{Insights into the sense-making process that influences the systemic re-organisation (Phase 3 )}

Sense-making is an ambiguous concept. In an attempt to better understand the process more clearly, a review of literature influenced by cognitive psychologists was undertaken. The dominant insights include selective attention (Drew, Vo \& Wolfe 2013; Simons \& Chabris 1999); culturally specific categorisation patterns (Chiu 1972; Unsworth 2005) and naturalistic decision-making (Klein 2008). This combination represents cognitive filters that influence subsequent emergence as people make sense of the world so that they can act in it.

The three cognitive filters suggest that the uptake of information contained in the A-3B-4C-T educational package and the application of that information to real-world challenges by the participants will probably be skewed - or biased - by a series of cognitive filters that reflect localised cultural dispositions. From the perspective of the pilot, this suggests that the way in which the A-3B-4C-T educational package and working realities were synthesised - and subsequently applied - by WWS reflect local cultural dispositions, rather than being a uniform, one-size-fits-all response.

From the perspective of complexity, this suggests that the cultural disposition of the participants represents a component of the 'initial conditions' that constrain the emergence as a system re-organises, see Table 2 . This suggests that future program designers should expect a variable, yet non-random, application of the new information by people working in the field. Allowing for this variability requires expecting that there may be both linear and non-linear cognitive absorptionand subsequent application of knowledge - rather than expecting a uniform, linear knowledge-to-action response and ensuring that both can be incorporated into the phases that follow.

\section{Systemic re-organisation (Phase 3 ) from a conceptual, 'academic' perspective}

The implication of the above combination of factors that influence the systemic re-organisation phase is that the primary probe will be interpreted and applied in idiosyncratic ways that reflect patterned biases. It also suggests that if the participants are provided with the autonomy to work through the sense-making phase without external interference, the likelihood is that the process is (1) hard wired to reflect the local cultural context, and (2) will generate systemically constrained interpretations about the primary probe (the A-3B-4C-T educational package) - which has the effect of promoting uniquely localised cognitive platforms from which new social practices can emerge. These platforms represent the basis of creative opportunities for future actions that make localised sense in particular social contexts. It also provided an opportunity to reflect on the ontological parameters of developmental discourses that were introduced above.

\section{Systemic re-organisation and the ontological parameters of broader developmental discourses}

One theoretical aspect of the pilot was to ask how to better understand the notion put forward by Cole (2003:332) that 'individuals' potentials evolve as emergent properties with social experience'. This was based on the concern during the design phases that both the independent and dependent actor presumptions about peoples' potentials highlighted by Cole (1999) were unnecessarily restrictive. During the pilot, it became evident that the WWS participants were demonstrating creativity as their 'social experiences' changed during the re-organisation process (Phases 1-4), indicating that they were demonstrating traits that can be associated with Cole's interdependency theorem. In order to conceptualise how this process of interdependency could be integrated into the Framework, the concept of exaptation was considered to be a likely candidate (Gould \& Vrba 1982).

\section{Exaptation}

Exaptation is a concept derived from evolutionary scholarship that explains how traits, or physical characteristics, evolved from earlier characteristics that originally had qualitatively different functions or purposes (Thanukos 2009). One example of this is the way in which birds' ability to fly emerged from the plumage found on some small dinosaurs. The dinosaur plumage was originally used for heat regulation, then coopted for display purposes and has - more recently, in evolutionary terms - been further co-opted, provisioning birds with the ability to fly (Norell \& Xu 2005).

In the context of human beings, this process is often described as the ability of people to innovatively repurpose artefacts for novel applications. Repurposing happens when a context alters sufficiently to demand innovations, or when an individual or collective imaginary prompts it. This provisions human beings with the unique ability to creatively devise new artefacts with exceptional speed - compared with the rest of the animal kingdom (Mars 2013). Examples include the repurposing of condoms to hold football socks up in rural Africa (Beninger \& Robson 2014); the use of music in HIV prevention (Banda \& Mambwe 2013) and - most commonly recognised - the repurposing of commercial pharmaceuticals (Batman, Hampson \& Hampson 2011).

The relevance of both the cognitive filters and repurposing of artefacts during the systemic re-organisation (Phase 3)

In this instance, WWS selected aspects of the A-3B-4C-T educational package that made sense to both themselves and their clients. WWS gradually repurposed aspects of this knowledge into artefacts - thereby reinforcing the tools and techniques attractor to promote the agreed end-condition of reducing the aggregate community viral load. Recent discussions with WWS facilitators indicate that the repurposing is continuing amongst their clients - which is a 
planned area of future research. For example, it was reported that the reinforcement of the 'viral load' attractor with one support group for people living with HIV has prompted a competition between the members about who can maintain the lowest viral load. Another example has emerged by reinforcing the origins of HIV attractor. The zoonotic origins of HIV are being used by the same group as a counter argument to local beliefs that HIV is caused by ritual defilement and should be treated through traditional approaches, rather than antiretroviral medications. Both of these examples demonstrates how two of the emergent attractors - the viral load and the origins of HIV - continue to be repurposed by WWS and their clients.

It also suggests that the assumptions made by the proponents of the first to fourth-generation of HIV prevention and management that people in communities are either independent or dependent actors may have been an overly simplistic view of human nature. In this instance, the community partners continue to repurpose some of the attractors through social experience which corresponds with Cole's interdependent actor category. The shift from 'individuals' potentials evolv[ing] as emergent properties with social experience' (Cole 2003:332), to exaptation, to the more pragmatic notion of repurposing provided an opportunity for soft indicators of change to be identified and evaluated during the pilot.

\section{Identifying the emergent attractors (Phase 4)}

Identifying the attractors required a straightforward analysis of narrative data using the causal layered analysis technique. The methodology described by Bishop and Dzidic (2014) was found to be easy to apply and the findings were satisfactory. However, the limitation of this approach is that it is confined to the level of a localised project. A subsequent literature review revealed that there is now propriety pattern detection software called SenseMaker ${ }^{\circledR}$ that is capable of analysing hundreds of micro-narratives which have been 'interpreted by the person who has told a story, therefore removing the need for - and the potential bias of $-\mathrm{a}$ third party to interpret the data' (emphasis in original, UNDP 2013:10). The software was developed by a company called Cognitive Edge and their training materials indicate that it is possible to identify attractors using this tool (Cognitive Edge 2008). Further research is required to establish if similar, yet much larger, projects can be attempted using this software.

\section{Decision-making: The Cynefin framework (between phases 4 and 5)}

The Cynefin framework was a functional heuristic and did enable appropriate decision-making categorisation by the partnership leadership as well as an opportunity to use the same findings as a mid-term monitoring and evaluation device.

\section{The leadership response (Phase 5)}

While the leadership response was appropriate - given the resources available to the partnership - it could be improved on. The potential impact of future action-oriented interventions of this nature would increase if strategic partners are incorporated from the outset. By identifying and securing partners who have the requisite skills and capacities to respond with real-time efficiency to emergent opportunities would have improved the pilot.

\section{A strategic reflection: is the framework a potential biosocial response that can contribute to ending AIDS?}

Joint United Nations Programme on HIV/AIDS UNAIDS do not define what the new biosocial response should look like. However, by extrapolating the concepts that contributed to the development of the Framework, the following can be suggested: (1) the introduction of new biomedical opportunities to end AIDS could be generating destabilisation within the South African HIV and AIDS environment; (2) the likelihood is that the complex HIV and AIDS environment is consequently undergoing a period of systemic re-organisation in response to the biomedical opportunities; and (3) the likelihood is that new attractors are emerging at multiple scales.

If it was possible to identify and respond to the emergence, then the South African NDoH and partners could respond with increased precision. However, this would require a dual focus on targeting not just people at risk (the surface descriptor), but also the discrete, attractors that mediate - or influence - the patterns of risk (the properties of the complex system). This is explored in more detail below.

\section{National destabilisation: The South African human immuno virus and acquired immune deficiency syndrome environment}

The South African HIV and AIDS environment is undergoing a profound shift - a form of destabilisation at a national scale - which is being enabled by the NDoH's commitment to Vision 90-90-90. This destabilisation is primarily being driven by the increased coverage of biomedical technologies and is likely to produce a broad portfolio of systemic, biosocial ripple effects along the entire treatment and care continuum (Whiteside, Cohen \& Strauss 2015). Some of these ripple effects will generate desirable emergent outcomes and contribute to achieving UNAIDS' end-condition of ending AIDS by 2030. However, there will also, inevitably, be undesirable emergent outcomes that will undermine the ambition. One possible example includes the way in which the biosocial ripple effects associated with pre-exposure prophylaxis (PrEP) medications could generate dual ripple effects: 'PrEP has the capacity simultaneously to increase judgement and stigma about sexual behaviour and to decrease fear and stigma in sexual encounters' (Brown et al. 2015:4).

Following the logic of the Framework - and assuming that there is consensus that the HIV and AIDS environment contains some non-linear, biosocial complexity - targeting the emergent, systemic re-organisation of the national HIV and AIDS environment as it responds to the destabilisation that is being generated by biomedical opportunities is a pragmatic management response. This is briefly discussed subsequently. 


\section{Targeting emergence}

Ideologically, UNAIDS - and by default the South African $\mathrm{NDoH}$ - takes an evidence informed position that it is necessary to target specific, at risk, populations. There is a pragmatic logic to this approach if the challenge is exclusively linear. However, as the epidemic is now becoming more 'complex' and 'nuanced' (UNAIDS 2015:178) and the 90:90:90 window of opportunity is closing, there is also a logic to respond to the non-linear factors that influence the South African HIV and AIDS environment. This would require identifying emergent attractors that affect the trajectory of the epidemic as affected people respond to the ripple effects of the biomedical opportunities.

Once the attractors that contribute to ending AIDS have been identified they can be reinforced and the attractors that do not contribute to ending AIDS can be dampened so that the submerged feedback dynamics - the properties of the system which influence the global end-condition of ending AIDS by 2030 are reinforced appropriately. By doing this, it will be possible to consolidate the social practices that contribute towards achieving the 90:90:90 end-condition of ending AIDS as they are developing - and simultaneously dampen social practices that detract from the 90:90:90 end-condition. This methodological design would be inclusive of both the surface descriptor and the submerged properties of the HIV and AIDS environment which suggests that the response would be (1) likely to make sense at localised scales; and (2) be sustainable, because the focus of the intervention would be the whole system - rather than just the surface descriptors.

The implications of this is that the new biosocial response to the changing HIV and AIDS environment needs to be responsive to both serendipity and rational opportunities to target both linear and non-linear emergence. By targeting the nuanced, emergent shifts so that they are being continually directed towards achieving the end of AIDS could represent an innovative biosocial addition to the 90:90:90 armamentarium. Expanding the application of the Framework - especially if it was augmented by pattern detection software such as SenseMaker ${ }^{\circledR}$ - could represent an opportunity to begin this process. From this perspective, the Framework does represent a nascent biosocial response that can make localised sense in variable contexts.

\section{Conclusion}

The development and application of the Taming Wicked Problems Framework has been presented. The Framework was designed to counter wicked problems that contain some non-linear complexity. Through the experiential learning of the pilot, the Framework has been developed into a more coherent entity. At a meta-theoretical level, the design was influenced by (1) going beyond the constraints of the independent and dependent actor categories associated with the first- to fourth-generation approaches to HIV management by opting for the interdependent category; and (2) managing systems that contain some non-linear, biosocial complexity.
The Framework does enable the constraints associated with the first- to fourth-generation approaches to biosocial HIV management to be reduced. It also provides a mechanism to manage systems that contain both linear and non-linear dynamics.

Concomitantly, UNAIDS have called for a new biosocial response to the epidemic and - by default, if the case material presented in the Gap Report is genuinely complex - this requires management strategies that are capable of working with non-linear complexity, rather than ignoring it. The Framework is capable of doing this and also enables discrete emergence to be targeted in ways that make sense in localised settings - rather than relying exclusively on targeting phenomena that are directly observable to experts who are unfamiliar with local contexts-to affect change. Consequently, it is suggested that this style of management of the HIV and AIDS environment may represent a nascent biosocial response that can contribute to the ambition of ending AIDS by 2030 .

\section{Acknowledgements}

This work is based on research supported by the National Research Foundation (NRF) and the Flemish Interuniversity Council for University Development Cooperation (VLIRUOS). The work was also made possible because of the cooperation of the Waterberg Welfare Society (WWS). The author would like to extend his appreciation to Mr Marota Aphane who assisted with much of the fieldwork and data analysis during his time with the University of Limpopo. Any opinion, finding and conclusion or recommendation expressed in this material are that of the author, and the NRF, VLIR-UOS and WWS do not accept any liability in this regard.

The original research was supported by the NRF and the Flemish Interuniversity Council for University Development Cooperation.

This article is a reflection on engaged research that was given ethical clearance by the Turfloop Research and Ethics Committee in 2013 (clearance number: TREC/ FSA/16/2013: IR).

\section{Competing interests}

The author declares that he has no financial or personal relationships which may have inappropriately influenced him in writing this article.

\section{References}

Ahern, J., 2011, 'From fail-safe to safe-to-fail: Sustainability and resilience in the new urban world', Landscape and Urban Planning 100(4), 341-343. https://doi.org/ 10.1016/j.landurbplan.2011.02.021

Auerbach, J.D., Parkhurst, J.O. \& Caceres, C.F., 2011. 'Addressing social drivers of HIV/ AIDS for the long-term response: Conceptual and methodological considerations', Global Public Health 6(Suppl 3), S293-S309. https://doi.org/10.1080/17441692.2 011.594451

Banda, F. \& Mambwe, K., 2013, 'Fighting HIV/AIDS through popular Zambian music', Muziki 10(Suppl 1), 1-12. https://doi.org/10.1080/18125980.2013.852738 
Batman, G., Hampson, L. \& Hampson, I.N., 2011, 'Lessons from repurposing HIV drugs: A prospective novel strategy for drug design', Future Virology 6(9), 1021-1023. https://doi.org/10.2217/fvl.11.75

Beninger, S. \& Robson, K., 2014, 'Creative consumers in impoverished situations', International Journal of Business and Emerging Markets 6(4), 356. https://doi. org/10.1504/ijbem.2014.065574

Bishop, B.J. \& Dzidic, P.L., 2014, 'Dealing with wicked problems: Conducting a causal layered analysis of complex social psychological issues', American Journal of Community Psychology 53(1-2), 13-24. https://doi.org/10.1007/s10464-0139611-5

Brown, G., Reeders, D., Dowsett, G.W., Ellard, J., Carman, M., Hendry, N. et al., 2015 'Investigating combination HIV prevention: Isolated interventions or complex system', Journal of the International AIDS Society 18(1), 20499. https://doi.org/ 10.7448 /ias.18.1.20499

Burman, C.J. \& Aphane, M., 2016a, 'Complex HIV/AIDS landscapes: Reflections on how "Path Creation" influenced an action-oriented intervention', Systemic Practice and Action Research 30(1), 45-66. https://doi.org/10.1007/s11213-0169385-4

Burman, C.J. \& Aphane, M.A., 2016b, 'Complex adaptive HIV/AIDS risk reduction: Plausible implications from findings in Limpopo Province, South Africa', South African Medical Journal 106(6), 571-574. https://doi.org/10.7196/SAMJ.2016. v106i6.10255

Burman, C.J., Aphane, M. \& Delobelle, P., 2015, 'Reducing the overall HIV-burden in South Africa: Is "reviving $A B C$ " an appropriate fit for a complex, adaptive epidemiological HIV landscape?', African Journal of AIDS Research 14(1), 13-28. https://doi.org/10.2989/16085906.2015.1016988

Burman, C.J., Aphane, M. \& Mollel, N., 2017, 'The Taming Wicked Problems Framework: Reflections in the making', Journal for New Generational Sciences 15(1), 51-73.

Campbell, C. \& Cornish, F., 2010, 'Towards a "fourth generation" of approaches to HIV/ AIDS management: Creating contexts for effective community mobilisation', AIDS Care 22(Suppl), 21569-21579. https://doi.org/10.1080/09540121.2010.525812

Chettiparamb, A., 2007, 'Dealing with complexity: An autopoietic view of the people's planning campaign, Kerala', Planning Theory \& Practice 8(4), 489-508. https://doi. org/10.1080/14649350701664655

Chiu, L.-H., 1972, 'A cross-cultural comparison of cognitive styles in Chinese and American children', International Journal of Psychology 7(4), 235-242. https:// American children', International Journal
doi.org/10.1080/00207597208246604

Churchman, C.W., 1967, 'Wicked problems', Management Science 14(4), B-141-B-146. https://doi.org/10.1287/mnsc.14.4.B141

Cognitive Edge, 2008, Designing a SenseMaker project, viewed 27 July 2016, from http://cognitive-edge.com/uploads/presentations/CE\%20Accreditation $\% 20$ SENSEMAKER\%20feb\%2008.pdf

Cole, K., 1999, Economy-environment-development-knowledge, Routledge, London.

Cole, K., 2003, 'Globalization: Understanding complexity', Progress in Development Studies 3(4), 323-338. https://doi.org/10.1191/1464993403ps068oa

Coleman, P.T., Vallacher, R.R., Nowak, A. \& Bui-Wrzosinska, L., 2007, 'Intractable conflict as an attractor: A dynamical systems approach to conflict escalation and intractability', American Behavioral Scientist 50(11), 1454-1475. https://doi.org/ intractability', American Behavio
10.1177/0002764207302463

Cornish, F., Priego-Hernandez, J., Campbell, C., Mburu, G. \& McLean, S., 2014 'The impact of community mobilisation on HIV prevention in middle and low income countries: A systematic review and critique', AIDS and Behavior 18(11), income countries: A systematic review and critique', AIDS

Dervin, B., 1998, 'Sense making theory and practice: An overview of user interests in knowledge seeking and use', Journal of Knowledge Management 2(2), 36-46. https://doi.org/10.1108/13673279810249369

Dettmer, H., 2011, Systems thinking and the cynefin framework - A strategic approach to managing complex systems, Goal Systems International, Port Angeles, WA.

Dickens, P.M., 2012, 'Facilitating emergence: Complex, adaptive systems theory and the shape of change', PhD thesis, Leadership and Change Program, Antioch University.

Drew, T., Vo, M.L. \& Wolfe, J.M., 2013, 'The invisible gorilla strikes again: Sustained inattentional blindness in expert observers', Psychological Science 24(9), 1848-1853. https://doi.org/10.1177/0956797613479386

Dunn, G., Brown, R.R., Bos, J.J. \& Bakker, K., 2016, 'Standing on the shoulders of giants: Understanding changes in urban water practice through the lens of complexity science', Urban Water Journal 14(7), 758-767. https://doi.org/10.108 0/1573062x.2016.1241284

Elford, W., 2012, 'A multi-ontology view of ergonomics: Applying the Cynefin framework to improve theory and practice', Work 41(1), 812-817. https://doi. org/10.3233/WOR-2012-0246-812

Goffman, E., 1974, Frame analysis: An essay on the organization of experience, Harvard University Press, Cambridge, MA.

Gould, S.J. \& Vrba, E.S., 1982, 'Exaptation - A missing term in the science of form', Paleobiology 8(1), 4-15. https://doi.org/10.1017/s0094837300004310

Govender, K. \& Poku, N.K., 2016, 'Fast-tracking HIV prevention: Scientific advances and implementation challenges', African Journal of AIDS Research 15(2), iii-viii. https://doi.org/10.2989/16085906.2016.1208944

Huertas, T.F., 2014, Safe to fail: How resolution will revolutionise banking, Palgrave Macmillan, London.

Hutchinson, M., Daly, J., Usher, K. \& Jackson, D., 2015, 'Editorial: Leadership when there are no easy answers: Applying leader moral courage to wicked problems', Journal of Clinical Nursing 24(21-22), 3021-3023. https://doi.org/10.1111/jocn.12968
Inayatullah, S., 1998, 'Causal layered analysis', Futures 30(8), 815-829. https://doi. org/10.1016/s0016-3287(98)00086-x

Klein, G., 2008, 'Naturalistic decision making', Human Factors 50(3), 456-460. https:// doi.org/10.1518/001872008X288385

Koch, J., Eisend, M. \& Petermann, A., 2009, 'Path dependence in decision-making processes: Exploring the impact of complexity under increasing returns', Business Research 2(1), 67-84. https://doi.org/10.1007/bf03343529

Leadership Training Resource Centre, 2014, The new A-3B-4C-T of HIV prevention A South African perspective, viewed 23 June 2015, from http://www.comminit. com/hiv-aids/content/new-3b-4c-t-hiv-prevention

Lee, M.E., 1997, 'From enlightenment to chaos: Toward nonmodern social theory', in R.A. Eve, S. Horsfall \& M.E. Lee (eds.), Chaos, complexity, and sociology: Myths, models, and theories, pp. 15-29, Sage, Thousand Oaks, CA.

Mars, M.M., 2013, 'Repurposing and legacy of innovation', in M.M. Mars \& S. Hoskinson (eds.), A cross-disciplinary primer on the meaning and principles of innovation, pp. 51-63, Emerald Group Publishing Limited, Bingley (UK).

Mayer, K.H., Shisana, O. \& Beyrer, C., 2016, 'AIDS 2016: From aspiration to implementation', The Lancet 387(10037), 2484. https://doi.org/10.1016/S0140$6736(16) 30621-3$

Norell, M.A. \& Xu, X., 2005, 'Feathered dinosaurs', Annual Review of Earth and Planetary Sciences 33(1), 277-299. https://doi.org/10.1146/annurev.earth.33.092203.122511

Olivier de Sardan, J.P., Diarra, A. \& Moha, M., 2017, 'Travelling models and the challenge of pragmatic contexts and practical norms: The case of maternal health', Health Res Policy Syst 15(Suppl 1), 60. https://doi.org/10.1186/s12961-017-0213-9

Pincus, D. \& Metten, A., 2010, 'Nonlinear dynamics in biopsychosocial resilience', Nonlinear Dynamics, Psychology, and Life Sciences 14(4), 353-380.

Piot, P., Bartos, M., Larson, H., Zewdie, D. \& Mane, P., 2008, 'Coming to terms with complexity: A call to action for HIV prevention', The Lancet 372(9641), 845-859. https://doi.org/10.1016/S0140-6736(08)60888-0

Ramalingham, B., 2013, Aid on the edge of chaos, Oxford University Press, Oxford.

Rickles, D., Hawe, P. \& Shiell, A., 2007, 'A simple guide to chaos and complexity', Journal of Epidemiology and Community Health 61(11), 933-937. https://doi.org/ 10.1136/jech.2006.054254

Rogers, K.H., Luton, R., Biggs, H., Biggs, R., Blignaut, S., Choles, A.G. et al., 2013 'Fostering complexity thinking in action research for change in social \& ecological systems', Ecology and Society 18(2), 1-12. https://doi.org/10.5751/es-05330 180231

Sharp, P. M. \& Hahn, B. H. 2011. 'Origins of HIV and the AIDS pandemic'. Cold Spring Harbor Perspect in Medicine [Online], 1. Available: http://www.ncbi.nlm.nih.gov/ pubmed/22229120 [Accessed 22 September 2015]. https://doi.org/10.1101/ cshperspect.a006841

Sharts-Hopko, N.C., 2013, 'Tackling complex problems, building evidence for practice, and educating doctoral nursing students to manage the tension', Nursing Outlook 61(2), 102-108. https://doi.org/10.1016/j.outlook.2012.11.007

Shiell, A., Hawe, P. \& Gold, L., 2008, 'Complex interventions or complex systems? Implications for health economic evaluation', British Medical Journal (Clinical Research Ed.) 336(7656), 1281-1283. https://doi.org/10.1136/bmj.39569. 510521.AD

Shisana, O., Rehle, T., Simbayi, L., Zuma, K., Jooste, S., Zungu, N. et al., 2014, South African National HIV Prevalence, Incidence and Behaviour Survey, 2012, HSRC Press, Cape Town.

Signal, L.N., Walton, M.D., Ni Mhurchu, C., Maddison, R., Bowers, S.G., Carter, K.N. et al., 2013, "Tackling "wicked" health promotion problems: A New Zealand case study', Health Promotion International 28(1), 84-94. https://doi.org/10.1093/ heapro/das006

Simons, D.J. \& Chabris, C.F., 1999, 'Gorillas in our midst: Sustained inattentional blindness for dynamic events', Perception 28(9), 1059-1074. https://doi.org/ 10.1068/p281059

Smith, D.K., Dearing, J.W., Sanchez, T. \& Goldschmidt, R.H., 2013, 'Introducing wicked issues for HIV pre-exposure prophylaxis implementation in the U.S.', American Journal of Preventive Medicine 44(1 Suppl 2), S59-S62. https://doi.org/10.1016/j. amepre.2012.09.057

Snowden, D.J. \& Boone, M.E., 2007, 'A leader's framework for decision making', Harvard Business Review 85(11), 68-76.

Stacey, R., 2003, Complexity and group processes: A radical social understanding of individuals, Brunner-Routledge, New York.

Stirzaker, R., Biggs, H., Roux, D. \& Cilliers, P., 2010, 'Requisite simplicities to help negotiate complex problems', Ambio 39(8), 600-607. https://doi.org/10.1007/ s13280-010-0075-7

Strogatz, S., 2003, Sync: The emerging science of spontaneous order, Hyperion, New York.

Sturmberg, J.P. \& Martin, C.M., 2008, 'Knowing--in medicine', Journal of Evaluation in Clinical Practice 14(5), 767-770. https://doi.org/10.1111/j.1365-2753.2008.01011.x

Sturmberg, J.P. \& Martin, C.M., 2009, 'Complexity and health - Yesterday's traditions, tomorrow's future', Journal of Evaluation in Clinical Practice 15(3), 543-548. https://doi.org/10.1111/j.1365-2753.2009.01163.x

Sturmberg, J.P. \& Martin, C.M., 2010, 'The dynamics of health care reform - Learning from a complex adaptive systems theoretical perspective', Nonlinear Dynamics, Psychology, and Life Sciences 14(4), 525-540.

Teeraananchai, S., Kerr, S.J., Amin, J., Ruxrungtham, K. \& Law, M.G., 2016, 'Life expectancy of HIV-positive people after starting combination antiretroviral therapy: A meta-analysis', HIV Medicine 18(4), 256-266, viewed 31 August 2017, from https://www.ncbi.nlm.nih.gov/pubmed/27578404 
Thanukos, A., 2009, 'How the adaptation got its start', Evolution: Education and Outreach 2(4), 612-616. https://doi.org/10.1007/s12052-009-0170-z

UNAIDS, 2014a, Fast track, Joint United Nations Programme on HIV/AIDS, Geneva.

UNAIDS, 2014b, The gap report, Joint United Nations Programme on HIV/AIDS, Geneva. UNAIDS, 2015, How AIDS changed everything, Joint United Nations Programme on HIV/AIDS, Geneva.

UNAIDS, 2016a, On the fast-track to end AIDS: 2016-2021 strategy, Joint United Nations Programme on HIV/AIDS, Geneva.

UNAIDS, 2016b, Prevention gap report, Joint United Nations Programme on HIV/AIDS, Geneva.

UNDP, 2013, Discussion paper. Innovation in monitoring and evaluation, United Nations Development Programme, New York.

Unsworth, S.J., 2005, 'Cultural influences on categorization processes', Journal of CrossCultural Psychology 36(6), 662-688. https://doi.org/10.1177/0022022105280509
Van Beurden, E.K., Kia, A.M., Zask, A., Dietrich, U. \& Rose, L., 2013, 'Making sense in a complex landscape: How the cynefin framework from complex adaptive systems theory can inform health promotion practice', Health Promotion International 28(1), 73-83. https://doi.org/10.1093/heapro/dar089

Vella, S., 2015, 'End of AIDS on the horizon, but innovation needed to end HIV', The Lancet HIV 2(3), e74-e75. https://doi.org/10.1016/s2352-3018(15)00023-5

Wals, A., 2007, 'Learning in a changing world and changing in a learning world: Reflexively fumbling towards sustainability', Southern African Journal of Environmental Education 24(1), 35-45.

Weaver, W., 1948, 'Science and complexity', Scientific American 36(4), 536-544.

Whiteside, A., Cohen, J. \& Strauss, M., 2015, 'Reconciling the science and policy divide: The reality of scaling up antiretroviral therapy in South Africa', Southern African Journal of HIV Medicine 16(1), 355. https://doi.org/10.4102/hivmed.v16i1.355

WWS, 2017, Waterberg Welfare Society, viewed 05 November 2016, from http:// www.waterbergwelfaresociety.org.za/ 